\title{
MATERIALISMO E IDEALISMO EN LA POÉTICA Y EN EL PENSAMIENTO POLÍTICO DE PERCY B. SHELLEY*
}

\author{
Pablo San Martín Varela \\ University of Edinburgh \\ san_wablo@hotmail.com
}

RESUMEN / ABSTRACT

Este ensayo es una lectura de las relaciones que hay entre el pensamiento político y estético del poeta romántico inglés Percy Bysshe Shelley. Su análisis se centra en las principales obras teóricas de este autor, pero también intenta establecer algunas relaciones generales con distintos momentos de su producción poética. La lectura desarrolla la contradicción que plantea la conjunción de un materialismo histórico de ascendencia godwiniana y un idealismo político de tradición humanista. En este contexto, propone que el vaso comunicante entre el pensamiento político y estético de Shelley es el presupuesto idealista de una continuidad entre conciencia, voluntad y realidad social, que le permite identificar su proyecto poético con su política. Por último, entiende esta contradicción dentro de la lógica del socialismo utópico tal y como éste ha sido explicado por Perry Anderson.

Palabras Clave: literatura inglesa, romanticismo, estética, política, socialismo utópico.

This essay presents a reading of the relationship between the poetics and political thinking of the English Romantic poet Percy Bysshe Shelley. The analysis centers on his main theoretical works, but also endeavors to establish some general relations to different moments of his poetic production. The reading develops the contradiction that is posed by the conjunction of a historical materialism of Godwinian origin and a political idealism more proper to the humanistic tradition. In this context, this paper proposes that the communicating vessel between

* Un año después de haber escrito este ensayo encontré dos libros que desarrollan ideas muy similares a las de mi argumento principal y que ahora aprovecho de recomendar al lector:

Scrivener, Michael Henry. Radical Shelley: The Philosophical Anarchism and Utopian Thought of Percy Bysshe Shelley. Princeton, N.J.: Princeton UP, 1982.

Foot, Paul. Red Shelley. Londres: Sidgwick \& Jackson, 1980. 
Shelley's political and aesthetic thinking is the idealistic assumption of continuity between conscience, will and social reality, which enables him to identify his poetic project with his politics. The essay concludes by understanding this contradiction within the logic of Utopian socialism, as it has been characterized by the historian Perry Anderson.

KEY WORDS: English literature, Romanticism, aesthetics, politics, utopian socialism.

Es un hecho bien conocido de la historia de la recepción del romanticismo inglés que Shelley "es ciertamente un poeta y un hombre capaz de producir respuestas contrarias" y que "causas para [esto] no son difíciles de encontrar" (Leader y O’Neill xi). Una de las principales causas podrían ser ciertas "contradicciones" que son "inherentes a su peculiar mezcla poética" (Gurney 302). Por un lado, está la "retórica incendiaria basada en los principios revolucionarios del filósofo protomarxista William Godwin" y, por otro, una poderosa e íntima tendencia al idealismo y a la visión (dream vision) que después encontró una expresión afín en la filosofía de Platón (y de Berkeley y Drummond) y en la poesía de Dante (Gurney 302-4). Pero esta contradicción no es exclusiva de su poesía, sino que permea toda su obra, incluyendo su prosa y su pensamiento político, estético y filosófico; y, a pesar de las declaraciones del mismo Shelley ${ }^{1}$, no forma parte de un desarrollo lineal que va desde el materialismo hasta el idealismo, sino que es una constante que puede rastrearse desde algunos poemas anteriores a Queen Mab (1812-13) hasta sus últimos escritos.

La influencia que el pensamiento materialista y determinista de Godwin ejerció sobre el joven Shelley fue profunda y lo marcó de por vida. Aunque posteriormente pudo haber cuestionado su racionalismo y su creencia en la perfectibilidad humana (y a pesar de los problemas personales que tuvieron por su relación con su hija Mary), Shelley siempre mantuvo su admiración por él: en A Philosophical View of Reform (1819-20) lo considera, junto con Hazlitt, Bentham y Hunt, como uno de aquellos "dignos de la época y de la causa" que "radiantes e irresistibles como el Sol del mediodía [...] dejarían a todos, excepto a las águilas que se atrevieran a mirar directamente su rayo, ciegos y confundidos" (671). En su magnum opus, Political Justice

En "On Life" (1818), Shelley dijo que "el materialismo es un sistema seductor para las mentes jóvenes y superficiales" y que "las más refinadas abstracciones de la lógica nos conducen a [...] afirmar que nada existe si no en la medida en que es percibido" (634). 
(1793), Godwin atribuía los principales y mayores males del mundo a las supersticiones fomentadas por la religión y a la distribución desigual de la riqueza, por lo que, entre otras cosas, "predicó la abolición de la propiedad privada, $[. .$.$] la eliminación de la religión patrocinada por el estado y la$ emancipación general de las masas trabajadoras" (Gurney 302). Shelley mantuvo y defendió estas ideas, junto con los análisis materialistas de la historia y de la sociedad que suponen, a lo largo de toda su carrera literaria, desde The Necessity of Atheism (1811), pasando por An Address to the People on the Death of Princess Charlotte (1817), hasta llegar a A Philosophical View of Reform y a A Defence of Poetry (1821).

En estas dos últimas obras se puede ver muy bien la contradicción que se plantea en la obra de Shelley entre el análisis y la comprensión materialista de la sociedad y de la historia, por un lado, y la formulación de una política idealista de la no violencia en la que "el cultivo de la imaginación", "de la verdad científica" y "de la indagación moral y metafísica" tiene un rol central (671), por otro. En A Philosophical View of Reform, Shelley explica, como antes había hecho en An Address to the People on the Death of Princess Charlotte, como, "aplicando sistemáticamente" "la estratagema del crédito público" "como un instrumento de gobierno" desde "que William III asumió el trono" en adelante (650), se estableció en Inglaterra "un sistema de doble aristocracia" (627) compuesta por la alianza de "capitalistas y terratenientes" (666). Este nuevo orden social, para poder mantener el "[creciente] número de aquellos que están ociosos en proporción a aquellos que trabajan", trajo consigo un sistema de explotación mucho peor que el anterior, en el cual a los trabajadores se les pagaba la mitad que antes y en el que además se obligaba a trabajar a viejos, enfermos y niños (651-4). De este modo fue que "la más baja y numerosa de todas las clases, cuyo trabajo [producía] todos los materiales necesarios para la vida," cada día "[comía] menos pan, [vestía] peores ropas, [se volvía] más ignorante, inmoral, miserable y desesperada", "más supersticiosa", y, lo peor de todo, "[se volvía] vengativa" (653-4). Sin embargo, en situaciones como ésta, en las que "[las clases trabajadoras] no pueden conseguir comida por su trabajo", "por una afortunada ley de la naturaleza", dice Shelley, "de un momento a otro se la toman por la fuerza" (654). Entonces se plantea la alternativa entre despotismo, reforma y revolución (654).

La opción de Shelley, como es bien sabido, es la reforma. Una reforma que sea "lenta", "gradual", "cautelosa" y, sobre todo, "pacífica", en la que "el pueblo se acostumbre a ejercer las funciones de la soberanía en la 
medida en que vaya adquiriendo posesión de ella" (666). En cambio, una revolución, según Shelley, solo traería consigo más desgracias que beneficios reales y duraderos: "Una República [...] por la violencia y el cambio brusco y repentino que necesariamente conlleva, correría el gran riesgo de decaer tan rápido como habría surgido" (662). Además, las revoluciones, como enseña el ejemplo de la Revolución Francesa, tienden por su propia naturaleza a traicionarse a sí mismas, ya que el medio que emplean, la violencia, es "altamente susceptible de ser pervertido para destruir la causa [que] supuestamente defendía" (673) y, lo que es aún peor, confirma la misma lógica del despotismo que intenta derrocar: "Una guerra civil [...] confirmaría en la mayor parte de la nación aquellos hábitos militares que han sido introducidos por nuestros tiranos y con los cuales la libertad es incompatible" (662-3). La reducción de las opciones a despotismo o revolución que hacen las clases dominantes le parece a Shelley solo una estrategia ideológica o una muestra más de su egoísmo y mezquindad: "A esta alternativa nos reduce el egoísmo de aquéllos que se burlan de nosotros al hacerlo" y, como es a ellos a quienes esta reducción "en su mayor parte les conviene y da provecho, es probable [...] que sea una exageración" (647-8). Para poder llevar a cabo la reforma deseada, Shelley cree que lo primero que hay que hacer, dado el estado de superstición, desunión y desmoralización del pueblo, es "ilustrar y unir a la nación y animarla con entusiasmo y confianza", de modo que de a poco "la minoría perciba los aproches del desarrollo de una fuerza irresistible" y "ellos mismos renuncien a sus distinciones usurpadas sin [perturbar] la tranquilidad pública [...] con una revolución" (668). En este proceso es muy importante para Shelley la participación de "poetas, filósofos y artistas" que "muestren [...] la inevitable conexión [que hay] entre la prosperidad nacional y la libertad, y el cultivo de la imaginación y [...] de la verdad científica, y el desarrollo profundo de la indagación moral y metafísica" (671).

Shelley desarrolla más detenidamente estas últimas ideas en A Defence of Poetry. Él ya antes había notado el desfase que se había producido en la "sociedad europea moderna" entre el progreso científico y material y el político y moral y había llamado la atención sobre cómo "el beneficio del aumento del poder del hombre" -obtenido tanto por el "grado de perfección" "alcanzado" por "las ciencias mecánicas" como por el "siempre creciente vigor" del "comercio"- "se convirtió, en consecuencia de las formas naturales (inartificial) en las que la sociedad sigue estando distribuida, en el instrumento de otros males adicionales" (641). En A Defence of 
Poetry, Shelley "atribuye" "el abuso [que se hace] de toda invención para reducir y combinar el trabajo hasta la exasperación de las desigualdades de la humanidad" a "un cultivo de las artes mecánicas desproporcionado con respecto a la presencia de la facultad creativa [i.e., la imaginación] que es la base de todo conocimiento" (696). Desde ese momento, pasa a entender la historia como una dialéctica entre la "Poesía", comprendida como "expresión de la Imaginación" (675), y "el principio del Yo (Self), cuya encarnación visible es el dinero" (696). La poesía, al ser una imagen del orden cósmico y un "eco de la música eterna" (679), produce "un tipo de placer" que "fortalece y purifica los sentimientos, amplía la imaginación y le da espíritu a la conciencia (sense)" (694). "Como el ejercicio fortalece el músculo" (682), la poesía vuelve a fortalecer la imaginación que se encuentra atrofiada. Esto permite combatir el "exceso del principio egoísta y calculador" que reina en el mundo (693), porque hace posible "el secreto de la moralidad": "el Amor; o salirnos de nuestra propia naturaleza e identificarnos con lo bello que existe en los pensamientos, las acciones o las personas que no son nuestros" (682). "Un hombre, para ser verdaderamente bueno", agrega Shelley, "debe imaginar intensa y ampliamente; debe ponerse en el lugar de otro y de muchos otros; debe hacer suyos las alegrías y los sufrimientos de su especie" (682). De este modo, "el yo (self) aparece como lo que es: un átomo ante el Universo" (698).

A partir de esta concepción del amor como simpatía universal ${ }^{3}$ y de la poesía como expresión y ejercicio de la imaginación que lo posibilita fue que Shelley pudo formular dentro de su sistema de pensamiento una continuidad entre la conciencia, la voluntad y la realidad que es característica del idealismo. Para explicar qué quiero decir con esto, resulta muy útil un pasaje en el que el mismo Shelley explica las relaciones de "los poemas de Homero y de sus contemporáneos" con "el sistema social" "de la infancia de Grecia" (680):

Homero encarnó la perfección ideal de su época en caracteres humanos; no podemos dudar que aquéllos quienes leyeron sus versos fueron

\footnotetext{
Ésta es la versión shelleyana del "viejo enemigo, la individualidad [selfhood] blakeana", que "sólo puede ser sometida" por "el poder expansivo y empático" de "una imaginación ética o religiosa" (Clubbe y Lovell 111). Lo que distingue esta versión de todas las demás es que tiene consecuencias históricas y sociales muy concretas.

En "On Love" (1818), Shelley había dicho que el amor "es el vínculo y la sanción que no sólo conecta un hombre con otro, sino que con todo lo que existe" (632).
} 
invadidos por una ambición de asemejarse a Aquiles, a Héctor y a Ulises: la verdad y la belleza de la amistad, del patriotismo y de la devoción perseverante hacia un objeto fueron develadas hasta lo más profundo en estas creaciones inmortales: la simpatía producida por tan grandes y adorables personificaciones debe haber refinado y ampliado los sentimientos de los auditores; hasta que por admirar imitaron y por imitar se identificaron con los objetos de su admiración (680-1).

Dicho en términos más generales, los seres humanos, cuando contemplan "la imagen de la divinidad en el hombre" (683) en toda su verdad y belleza, como aparece en la poesía, sienten el profundo deseo, motivado por la simpatía o el amor, de igualarse a esa perfección humana ideal y basta solo con esto para que lo logren. Podría decirse, por lo tanto, que en el pensamiento de Shelley se produce una continuidad perfecta entre lo que una persona cree que ella misma y el mundo deberían ser (conciencia), lo que quiere o desea ser y que ocurra (voluntad) y lo que efectivamente es y ocurre (realidad). En A Philosophical View of Reform, él había dicho que la "igualdad de posesiones", el "principio elemental" y el "objetivo" de grandes hombres como "Platón, Cristo y Rousseau y [...] Godwin", es "un objeto que es, porque lo queremos, y que puede ser, porque lo esperamos (hope) y lo deseamos, y que tiene que ser, si las futuras generaciones de ilustrados lo persiguen sincera y fervientemente" (664). Esta continuidad entre conciencia, voluntad y realidad es la base de la política idealista y del proyecto poético de Shelley, que, en última instancia, son una y la misma cosa.

En el caso de la Europa moderna, el gran problema para Shelley era cómo "[acomodar] las formas existentes de acuerdo a las cuales la humanidad se encuentra dividida a aquellas normas de libertad e igualdad que [son] los principios elementales según los cuales la felicidad que resulta de la unión social debería ser producida y distribuida" (641). En A Defence of Poetry, este problema ya no concierne tanto al conocimiento (la "verdad científica" y la "indagación moral y metafísica"), porque "tenemos más conocimiento moral, político e histórico que el que sabemos cómo reducir a la práctica" (695). Este conocimiento, "el principio de igualdad", "había sido descubierto y aplicado por Platón en La República", después fue "divulgado" por Jesús (690) y, aunque fue "rápidamente distorsionado" y "pervertido" por la Iglesia Católica "para mantener la opresión” durante la Edad Media (637), es el mismo que ha estado siendo "restablecido" por los filósofos desde el Renacimiento y ha servido como base para la "filosofía política" moderna (640-1). Lo que Shelley encontraba realmente necesario para su época era 
que "la facultad creativa [imaginara] aquello que [ya sabíamos]" (695). Por lo tanto, la función política de la poesía, más que explicar o divulgar una determinada doctrina moral, filosófica o política ${ }^{4}$, consiste en encender el deseo de hacer realidad ese "sistema de libertad e igualdad" (637) que desde hace tanto tiempo se ha predicado, y formar, por medio del ejercicio de la imaginación, ciudadanos competentes que puedan lidiar con "las difíciles e inflexibles realidades de la vida" y "[ajustar] nuestras teorías a la práctica inmediata" (664): éste es el sentido profundamente romántico y shelleyano en que los poetas son "educadores" (teachers) (677). De esta manera la poesía puede ser el motor de la reforma, de ese "progreso tranquilo pero inevitable" que Shelley tan ardientemente deseaba (663). Las contradicciones entre idealismo y materialismo en el pensamiento de Shelley culminan en la formulación de una 'política estética' o 'poética' que, como bien señala Stephen Gurney, "[tiene] más en común la política visionaria de la égloga cuarta de Virgilio o con las profecías de Isaías sobre el milenio de paz y felicidad en el que el león se tenderá junto al cordero" que con las "aspiraciones [...] de William Godwin, Thomas Paine y otros escépticos racionalistas de la época revolucionaria" (Gurney 303).

Durante toda su carrera, Shelley intentó mantener una unidad entre su pensamiento político y estético y su praxis poética, por lo que muchas de estas ideas quedaron plasmadas tanto en la forma como en el contenido de sus poemas y dramas. Muchos críticos están de acuerdo en interpretar a Alastor (1815), el Espíritu de la Soledad, como una expresión de "la necesidad y de la limitación inherente" del "solipsismo" y de la "Individualidad". Ahí Shelley muestra, a través de "la autodestrucción del Poeta-héroe", "el precio excesivo de una búsqueda" que involucra una "alienación de los otros" (Bloom 4, 20 1, Gurney 304-5). Prometheus Unbound (1818-20), por su parte, expresa la continuidad entre conciencia, voluntad y realidad, que conecta el pensamiento político y la poética de Shelley. Como lo pone Gurney, "Prometheus Unbound es el drama del [...] despertar [del ciudadano]" (Gurney 307). En un primer momento, Prometeo se da cuenta de que "su anterior maldición sobre Júpiter solo perpetúa el reino despótico contra el cual [él] lucha" y comprende de ese modo que "el odio [...] es la peor tiranía de todas" (Gurney 307). En el lenguaje de A Philosophical View of Reform podría decirse que Prometeo

\footnotetext{
4 "Aborrezco la poesía didáctica" había dicho en el "Prefacio" a Prometheus Unbound (232).
} 
primero se da cuenta de que la revolución y violencia política se han vuelto "periódicas, crónicas e incurables" "como en Constantinopla", donde "los tumultos y las insurrecciones [...] terminaron siendo compatibles con la permanencia del mal causante, del cual ellos podrían haber sido la determinación fundamental" (670-1), y comprende, de este modo, que ambas solo confirman la lógica del despotismo que pretenden derrocar (662-3). Tomar conciencia de esto le permite a Prometeo renunciar a la venganza y, "respondiendo a la opresión con paciencia, tolerancia, perdón y amor, finalmente triunfa" (Gurney 307). En ese momento es que "Demogorgon, la dialéctica de la historia, asciende desde el abismo y detiene la historia, completando de este modo en la sombra macrocósmica lo que Prometeo, con su renuncia, inaugura en el microcosmos de la imaginación individual" (Bloom 21). Pero la continuidad entre conciencia, voluntad y realidad, aunque ejemplarmente plasmada en Prometheus Unbound, no aparece ahí por primera vez en la poesía de Shelley. Esta continuidad puede rastrearse hasta poemas anteriores a Queen Mab, como los sonetos "On Launching Some Bottles Filled with Knowledge into the Bristol Channel" y "To a Balloon, Laden with Knowledge". Estos poemas son muy reveladores con respecto al carácter racionalista e ilustrado que tuvo la política idealista de Shelley en una etapa temprana. En ellos queda absolutamente claro que él creía que bastaba con que "algún alma libre de nacimiento" "encontrara" la "carga" que él había mandado para que ella "encendiera" la "llama celestial" de la "Libertad" "hasta que su resplandor [brillara] de polo a polo" (9). Podría decirse, entonces, que los mismos actos de arrojar las botellas al Bristol Channel o de echar a volar los globos eran para Shelley actos políticos. Pero es necesario tener siempre presente que las ideas políticas y estéticas de Shelley no se expresan solo en el contenido de sus obras poéticas, en lo que él llamaba los "bellos idealismos de excelencia moral" (232), sino que también, y sobre todo, en su forma. La experimentación formal que es común a todo el romanticismo cobra una significación muy particular en la obra de Shelley: de acuerdo a su poética, cumple una función política y social, además de estética, en la medida en que fortalece y amplía la sensibilidad y la imaginación del público. Y hay quien ha dicho que "la mezcla genérica" de Prometheus Unbound, junto con la de The Prelude de Wordsworth y la de Don Juan de Byron, es uno de "los más audaces y sofisticados experimentos formales de la poesía romántica inglesa" (Curran 163).

Creo que resultaría muy adecuado y productivo interpretar esta contradicción entre materialismo e idealismo que se plantea en la obra de Shelley dentro 
de la lógica general del socialismo utópico. Ya en 1888, Eleanor Marx había "reclamado" a Shelley como "un Socialista de nuestros días", diciendo que "él vio más claramente que Byron, que parece apenas haberlo notado, que la epopeya del siglo XIX iba a ser la lucha entre la clase productora y la poseedora" y que "este solo hecho [...] lo remueve de la categoría de los Socialistas Utópicos" (Aveling y Marx). Esto es cierto con respecto a su análisis y su comprensión de la sociedad y de la historia: su explicación de que el sistema social de su época fue establecido por una alianza entre terratenientes y capitalistas, su denuncia de que la deuda nacional era solo un artilugio empleado para justificar la explotación, su distinción entre dos tipos de propiedad (trabajo y capital), entre dos clases sociales principales (los productores y los propietarios), etc. Pero no lo es, de ninguna manera, con respecto a su política. En palabras de Perry Anderson, lo que distingue al 'socialismo utópico' es que
Al presentarse como un programa para la reforma ética de la humanidad en su totalidad, carecía de un "operador" histórico capaz de mover la enorme carga de miseria material que tan fervientemente denunciaba. Precisamente porque buscaba liberar "de una sola vez" a toda la humanidad de la esclavitud [...] no tenía manera de localizar las líneas de división dentro de la humanidad que podrían hacer surgir la nueva civilización. Su universalismo conciliador-el evangelio de una religión secular, según lo formularon sus fundadores-excluía el conflicto social como principio central del cambio político: de ahí que tuviera que recurrir necesariamente a la conversión moral como un substituto para él (Anderson 94).

Bajo la forma de socialismo utópico, Shelley y el romanticismo continuaban una larga tradición de idealismo político por el cual los intelectuales y artistas humanistas desde el Renacimiento en adelante empezaron a ser marginados de la política y de la vida pública en general'. En cambio, el 'socialismo científico' o 'de nuestros días', surgido a mediados del siglo XIX, se caracterizó por haber formulado una política realista o materialista que

[salió] de este punto muerto identificando el lugar de un agente social particular, enraizado en formas de producción económica históricamente específicas, como el punto arquimediano desde el cual 
el viejo orden podía ser derrocado -la posición estructural ocupada por la clase trabajadora industrial creada por la llegada del capitalismo. Ese proceso, por definición, implicaba la más tajante división de la humanidad en dos campos políticos opuestos y una guerra endémica entre ellos (Anderson 94).

¿Reforma o revolución? (1900) de Rosa Luxemburgo puede ser considerado un ejemplo paradigmático de las respuestas que este nuevo tipo de socialismo dio a la política idealista del socialismo utópico.

Ahora bien, el desarrollo posterior de la historia social y política de Europa y del resto del mundo, del cual surgió este nuevo tipo de socialismo, hizo demasiado obvio que el proyecto literario expansivo del romanticismo, que alcanza su formulación más radical en la obra de Shelley, no era posible. Las teorías de Shelley acerca de que al ver avanzar el movimiento social los opresores cederían el poder que habían adquirido injustamente sin oponer resistencia, o de que un soldado se detendría ante una multitud que espera su ataque pacíficamente de brazos cruzados, resultaron no ser ciertas. Tampoco vino de ningún "cielo superior" un Demogorgon para defender a los oprimidos y realizar materialmente su triunfo moral y subjetivo. El mismo caso de "la junta anarquista de Chicago" que invoca Eleanor Marx para defender el socialismo de Shelley -en el que "no hubo ningún levantamiento, ni se habló de levantarse, no hubo uso de fuerza física por parte del pueblo, ni amenazas de usarla", y, "sin embargo, siete hombres fueron condenados" (Aveling y Marx)- es una prueba más de que su política estaba fundada "sobre la base de supuestos manifiestamente irrealistas acerca de cómo se comportan las personas - una vez que están organizadas en clases antagonísticas" (Anderson 103). Con una seguidilla progresiva de otros eventos históricos como éste quedó en evidencia el idealismo de la psicología social en la que está basada toda política de una reforma pacífica y gradual, cuyo motor principal sea la estimulación de la razonabilidad y la buena voluntad de las personas a través de la ciencia, la filosofía y el arte. Por esto es que $A$ Defence of Poetry, en los "apenas doce años" que la "separaron" "del ensayo de [John Stuart] Mill" "¿What is Poetry?”, pasó a ser "inimitablemente propia de su tiempo" (Curran 167). La historia literaria posterior "traza una pérdida de compromiso cada

\footnotetext{
"En breve, la rebelión de Prometeo está basada en la existencia de un cielo superior con respecto al cual implícitamente el reino de Júpiter es juzgado" (Gurney 308).
} 
vez mayor, una involución a la autocontemplación formal como un refugio ante la cultura burguesa," y, como señala brillantemente Stuart Curran,

\begin{abstract}
la división habitual que se hace en la poesía francesa del siglo XIX entre romanticismo y simbolismo, aunque notoriamente difícil de ubicar, da cuenta de una conciencia generalizada de que el romanticismo, a pesar de verse obligado a esperar el fin de las Guerras Napoleónicas, nunca se enorgulleció ni se complació de su falta de compromiso (Curran 178).
\end{abstract}

La poesía romántica en general, y sobre todo la de Shelley, se distinguió por haber estado siempre intentando ir más allá de sí, hacia la sociedad, la historia, la filosofía, la religión, la ciencia, la ética, la economía política, etc. El romanticismo acabó en el momento en que la experiencia histórica desmintió el fundamento teórico de esta poética expansiva.

Al terminar esta lectura de su pensamiento político y de su poética, es bueno recordar que en muchos momentos Shelley parece haber sospechado que alguna fuerza histórica inquietante y desconocida, algo así como los intereses de clase o una voluntad de poder, podía interferir o incluso destruir la armoniosa continuidad que él suponía que había entre conciencia, voluntad y realidad. En A Philosophical View of Reform ya había notado que "hay una afinidad secreta entre la Destrucción y el Poder" (672) y que, si una "clase de hombres" "hereda el derecho de legislar y juzgar", "los principios de la naturaleza humana" los "llevan" "a ejercer[lo] en su propio beneficio y en detrimento de aquéllos que no forman parte de su propia clase" (642). En Triumph of Life (1822), las dudas y sospechas de Shelley se expresan en el hecho de que, "a pesar de haber tenido la visión de una diosa radiante en su juventud, $[\ldots]$ Rousseau no pudo evitar unirse a la desquiciada procesión de personas mundanas, codiciosas, descontentas y entregadas a nada más que a sus apetitos (appetitive)" (Gurney 314). Pero estas dudas y sospechas nunca fueron suficientes como para llevarlo a reformular las ideas centrales de su pensamiento político y estético, ni muchos menos su proyecto poético ni su creencia en el poder de acción histórica de la poesía. Quizás la respuesta a la pregunta “¿Entonces qué es la vida?” (621), que el poema deja inconclusa, hubiera dado alguna pista más sobre esto. Lo que sí es seguro es que, a pesar de todo su utopismo, una voluntad política radical e intransigente llevó muchas veces a Shelley a sacar conclusiones propias del realismo político: aunque afirmó sin dudar que "ningún amigo de la humanidad y de su país puede desear que ocurra una crisis de este tipo [i.e., una revolución]", tenía 
muy claro que, "mucho menos, habiéndose producido, puede demorarse en decidir bajo qué bandera alinear su persona y su poder" (666). Por esto es que Marx dijo:

La verdadera diferencia entre Byron y Shelley es ésta: que aquéllos que los entienden y los aman se alegran de que Byron muriera a los treintaiséis, porque si hubiera vivido más se habría vuelto un burgués reaccionario; pero, en cambio, se lamentan de que Shelley muriera a los veintinueve, porque él era esencialmente un revolucionario y siempre se habría mantenido en la vanguardia del Socialismo (Cit. en Aveling y Marx).

Shelley estuvo más cerca que todos los demás románticos de vislumbrar el verdadero lugar que tenían los intelectuales y los artistas dentro del desarrollo histórico de la sociedad capitalista moderna, pero su profundo y ferviente humanismo le impidió llevar sus intuiciones y sospechas hasta sus últimas consecuencias tanto políticas como estéticas. Para haber hecho esto, tendría que haber superado los límites históricos del romanticismo tal y como lo conocemos.

\section{BIBLIOGRAFÍA}

Anderson, Perry. In the Tracks of Historical Materialism. Verso: London, 1983.

Aveling, Edward y Eleanor Marx. "Shelley and Socialism". Marxists.org. Diciembre 2010 http://www.marxists.org/archive/eleanor-marx/1888/04/shelley-socialism.htm.

Bloom, Harold. "Introduction" ("The Internalization of Quest-Romance”). English Romantic Poetry. Comp. Harold Bloom. Filadelfia: Chelsea House Publishers, 2004. 1-23.

Clubbe, John y Ernest Lovell. “English Romanticism: The Grounds of Belief”. English Romantic Poetry. Comp. Harold Bloom. Filadelfia: Chelsea House Publishers, 2004. 101-115.

Curran, Stuart. "Form and Freedom in European Romantic Poetry". English Romantic Poetry. Comp. Harold Bloom. Filadelfia: Chelsea House Publishers, 2004. 163-184.

Gurney, Stephen. "Byron and Shelley". English Romantic Poetry. Comp. Harold Bloom. Filadelfia: Chelsea House Publishers, 2004. 289-317.

Hauser, Arnold. "The Age of Political Realism". The Social History of Art. Tomo 2. Londres: Routledge, 1999. 96-131.

Leader, Zachary y Michael O’Neill. “Introduction”. The Major Works of Percy Bysshe Shelley. Ed. Percy Shelley. Nueva York: Oxford University Press, 2003. xi-xxiv.

Shelley, Percy. The Major Works of Percy Bysshe Shelley. Ed. Zachary Leader y Michael O’Neill. Nueva York: Oxford University Press, 2003. 